\title{
Low Velocity Impact Fatigue Studies on Glass Epoxy Composite Laminates with Varied Material and Test Parameters-Effect of Incident Energy and Fibre Volume Fraction
}

\author{
FRP Pilot Plant \\ Materials Science Division \\ National Aerospace Laboratories \\ Bangalore: 560017 , India
}

BUOYSRI KHAN,* R. M. V. G. K. RAO** AND N. VENKATARAMAN*

ABSTRACT: An effort was made to study the effects of fibre volume fraction and incident energy on the impact damage tolerance of composite laminates subjected to low velocity impacts at constant strike velocities. Repeated drop tests were condúctéd using an in-house built drop weight impact tester. Delamination area was used as a parameter for quantifying damage while the number of drops (impacts) to failure used 'to assess the damage tolerance limits. The delamination area was found to increase and then saturate after a certain number of drops. Impact fatigue studies showed the existence of a critical incident energy $\left(E_{c}\right)$ around which design of composite structures can be based. Also the minimum incident energy required to fracture the sample in a single impact $\left(E_{S D T}\right)$ was evaluated from the data. One of the interesting observations made was that for any given incident energy, the delamination area was found to be minimum at a certain fibre volume fraction ( 0.5 in this case) of the laminate. This was explained on lines of failure mechanisms reported earlier.

\section{INTRODUCTION}

$T^{T}$ IS WELL known that fibre reinforced polymer matrix composites undergo 1 damage through a complex process $[1,2,3]$ when impacted by a solid object or a projectile. This is mainly due to complex interfaces occurring in laminated composites. Applications where composites are susceptible to impact by foreign objects are of particular concern to designers of aerospace structures. Unfortunately in many cases consideration of impact resistance of the material is conspicuously absent in the design either due to the complications arising out of its

- Dept. of Metallurgy, Karnataka Regional Enginecring College, Surathkal, India.

**Author to whom all correspondence should be addressed. 
accounting or absence of appropriate information in this field for such materials. Therefore to utilise composites to our full advantage, their response to impact must be assessed to fairly predictable levels.

Impact induced damage in a composite is a very complex phenomenon consisting of a variety of failure modes [1,2,3] that mainly include delamination [4,5], fibre breakage, fibre pullout and total failure of the laminate. The high cost and difficulty in performing the widely discussed $[6,7]$ compression after impact tests using sophisticated instrumented drop weight impact testers as a measure of damage tolerance has necessitated the development of a more convenient and less expensive damage assessment test procedure using an uninstrumented drop weight impact tester (UDWIT) as adapted in the present studies. Repeated drop testing or impact fatigue is one of the candidate techniques $[6,8,9]$. Lhymn [8] has derived a lifetime equation of impact fatigue for PPS/glass composites and analysed it statistically to predict the engineering lifetime for design purposes and also a minimum impact energy for failure was envisaged. Jang et al. [9] conducted repeated low velocity impact tests on PPS and epoxy composites using an instrumented drop weight impact tester and identified threshold incident energy $E_{\mathrm{r} k}$ and critical impact cycles $N_{c}$ which were used as indices for ranking of glass, kevlar and graphite fibre reinforced plastics. Wyrick and Adams [6] measured the residual tensile and compressive strengths of specimens cut from composite plates subjected to repeated impacts at various incident energy levels.

However reports on repeated drop test (RDT) data using uninstrumented drop weight impact testers (UDWIT), which can in a way provide designers with inexpensive and simple approaches of designing withrcomposites are not available in open literature. Also techniques of predicting safe incident impact energy levels for composites in service are scant. . $^{\prime}$ tit $p$

A systematic study involving the effects of both(material and test parameters on the impact damage tolerance of laminated corrposites using an in-house built UDWIT was used by the authors and result's ireported. The approach to the problem should therefore be to study the effectsi of material parameters like fibre volume fraction, reinforcement form and its weave style as well as test parameters on the impact fatigue behavior of composites (see Table 1). The first step in this direction was to evaluate the effects of fibre volume fraction $\left(V_{f}\right)$ and incident impact energy $\left(E_{\text {in }}\right)$ on the impact fatigue behavior of glass-epoxy laminates and these results are presented in this paper. Further an attempt was made to com-

Table 1. Factors affecting impact data.

\begin{tabular}{ll}
\hline Test Parameters & Material Parameters \\
\hline Incident energy & Matrix (brittle/toughened) \\
Incident velocity & Reinforcement type (carbon/glass/kevlar/hybrids) \\
Impactor geometry & Weave style \\
Impactor material & Fibre content \\
Specimen support type & Thickness \\
\hline
\end{tabular}


ment on some of the interesting characteristics of impact fatigue curves so obtained.

\section{EXPERIMENTAL}

\section{Test Laminate Preparation}

The test laminates were prepared by a modified compression moulding technique [10]. The matrix used was a room temperature cure epoxy resin system (LY 5052 and HY 5052) supplied by Ciba Giegy (India) Ltd. Reinforcement used was E-glass satin weave fabric, 8-mil thick. Different number of layers were moulded to the same cured thickness $(2 \mathrm{~mm})$ to yield laminates of three different volume fractions $(0.3,0.5,0.7)$. From these laminates test specimens of size 90 $\mathrm{mm} \times 90 \mathrm{~mm}$ were cut using a diamond edged cutter for repeated drop testing.

\section{Test Procedure}

The energy absorption in a composite depends on an array of factors that impart specific history to the material under test [11,12]. It is thus very important that data comparisons between various composites be made with these factors clearly specified (which unfortunately is not the case very often) to avoid conflicting results. These may be broadly classified into test parameters and material parameters as given in Table 1.

In the present studies the material parameter chosen was the fibre volume fraction and test parameter, the incident energy. A stainless steel hemispherical tup of $12.5 \mathrm{~mm}$ diameter was used throughout the experiments. The specimen was clamped along the edges so as to leave a central circular test area of $11.4 \mathrm{sq} . \mathrm{mm}$. All the impacts were carried out at a constant impact velocity of $2.89 \mathrm{mts} / \mathrm{sec}$. The impact tester developed at the FRP Pilot Plant, NAL and used in the studies is shown in Figure 1.

The test procedure consisted of repeatedly impacting the clamped specimen till penetration occurred. Delamination area growth and number of drops to failure $\left(N_{f}\right)$ were chosen as damage tolerance assessment parameters and noted for different $E_{i n}$ values and for specimens of three different $V_{f}$ values. The delamination area (whitened region created upon impact) was traced to a graph sheet and areas measured as a function of the drop number.

\section{RESULTS AND DISCUSSIONS}

The data are plotted as $E_{i n}$ vs $N_{f}$ and delamination area vs drop number for different $V_{f}$ values and delamination area vs $V_{f}$ for different $E_{i n}$ values. The observed results are discussed in the following paragraphs.

Effect of $E_{i n}$ on $N_{f}$

Figure 2 shows the plot of $E_{i n}$ vs $N_{f}$ for specimens of three different $V_{f}$ 's representing resin rich and fibre rich composites. It can be seen that all the curves (the impact fatigue curves) exhibit a characteristic knee point (Figure 2), correspond- 


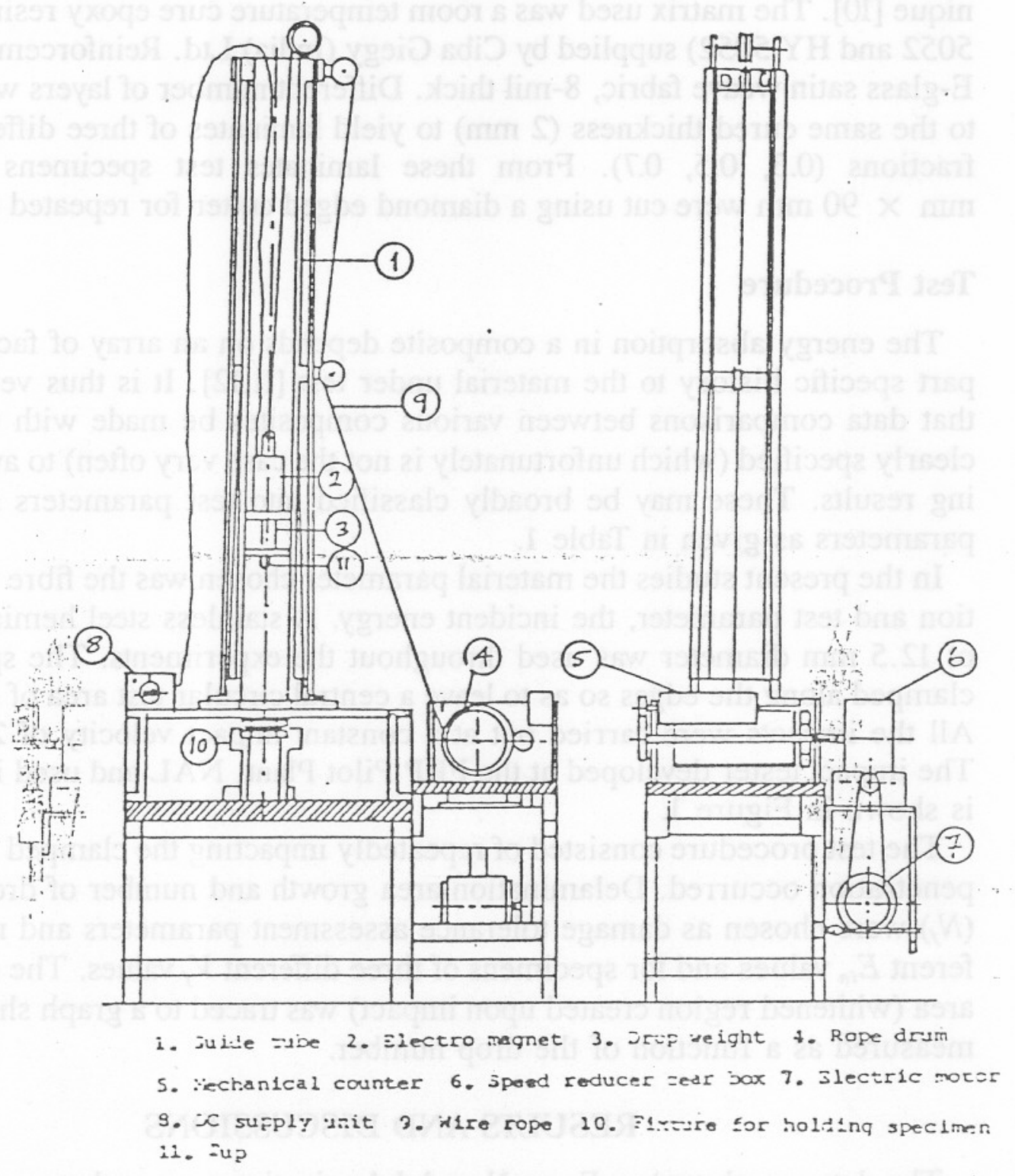

Figure 1. The NAL drop weight impact tester. 


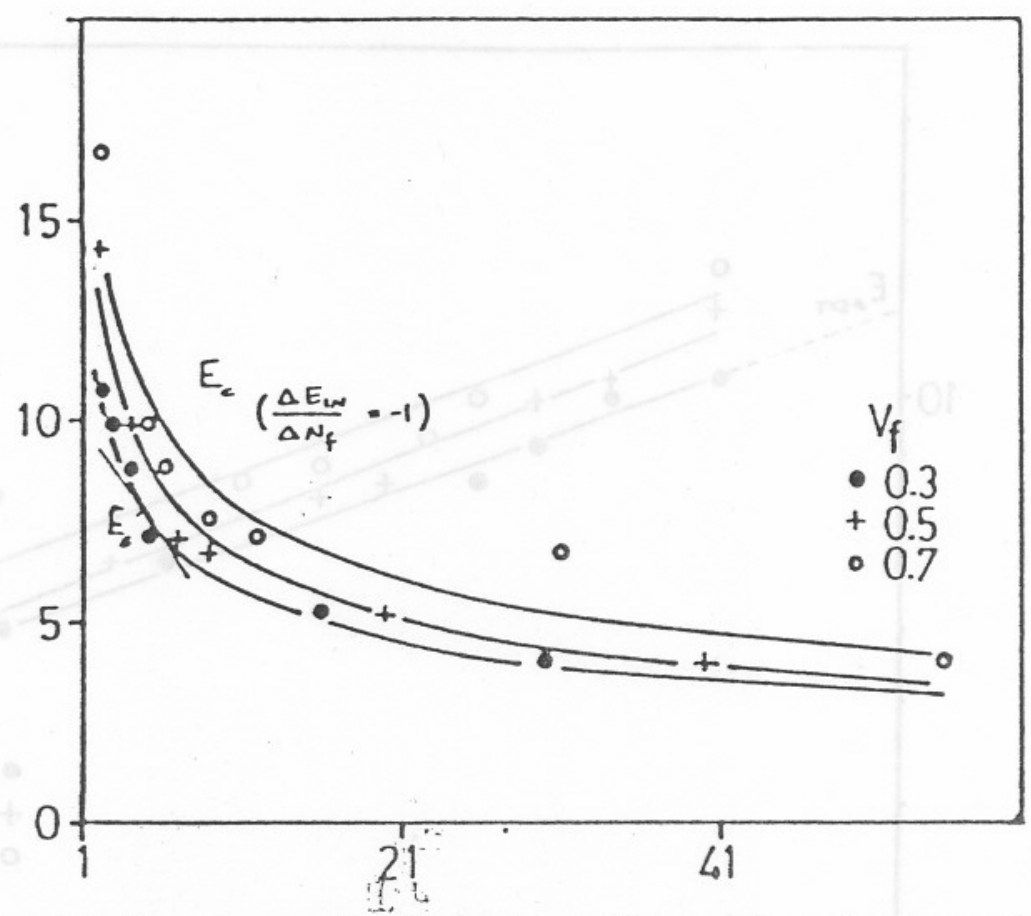

Figure 2. Impact fatigue curves forilaminates of three different volume fractions. X-axis: number of drops to failure $\mathrm{N}_{\mathrm{f}} ; \mathrm{Y}$-axjsifincident energy $\mathrm{E}_{\text {in }}$ joules.

$$
\rightarrow \rightarrow
$$

ing to which a critical incident energy $E_{c}$ can be identified as that value for which $\Delta E_{i n} / \Delta N_{f}-1$. It is clear that $N_{f}$ decreases drastically for values of $E_{i n}>E_{c}$, signifying damage susceptibility and the vice versa. A design incident energy limit $E_{d}$ can therefore be evolved such that $\left(E_{d} / E_{c}\right)<1$. The choice of the ratio $\left(E_{d} / E_{c}\right)$ has to be chosen discretely by the designer, considering the probability of impacts in service. Higher the probability of impacts, lower should be $\left(E_{d} / E_{c}\right)$. If the expected $E_{i n}>E_{c}$, then an optimization among various material parameters ( $V_{f}$, thickness, matrix toughness, fibre nature, etc.) has to be struck in the design process.

Further, if tests are conducted at lower $E_{i n}$, an incident energy level may be identified below which $N_{f}$ tends to infinity. This incident energy level is thus analogous to endurance limit as found in S-N diagrams used for fatigue analysis. However due to practical considerations in conducting so many impacts, such ar attempt was not made.

Analysing the plots shown in Figure 2, it can be possible to establish a correla. tion between $E_{i n}$ and $N_{f}$ through a theoretical relationship. From the data obtainec it is seen that $E_{i n}$ varies inversely as the power of $N_{f}$,

$$
\begin{gathered}
E_{i n} \propto 1 / N_{f}^{b} \\
E_{i n}=A\left(N_{f}\right)^{-b}
\end{gathered}
$$

where $A$ is the constant of proportionality and serves as a parameter for quantify ing damage tolerance. This can be better understood when we substitute $N_{f}=1$ Then $E_{i n}=A$, which is nothing but the minimum energy required to fracture thi 


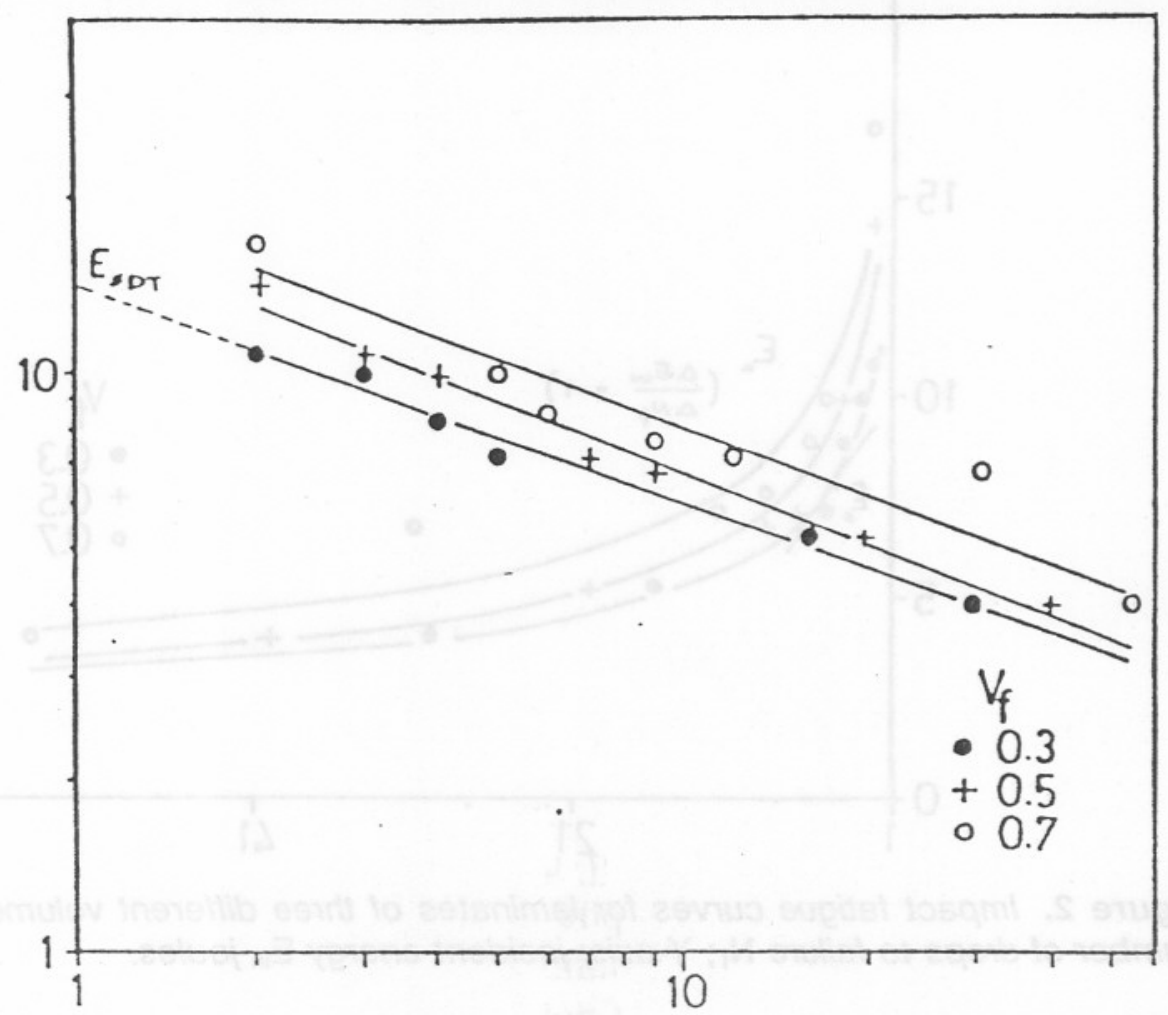

Figure 3. Log-Log plot of impact fatigue data for laminates of three different volume fractions. X-axis: number of drops to failure $\mathrm{N}_{1} ; \mathrm{Y}$-axis: incident energy $\mathrm{E}_{\text {in }}$ joules.

specimen in a single impact.(S.D.T. value) at the given incident energy. From the log-log plot (Figure 3) swe see that the slope $(b)$ is more or less constant fortar given set of material parameters. For the range of volume fractions investigatedub: $b$ varied between -0.37 and -0.41 . The values of constants $A$ and $b$ for differentere $V_{f}$ values are as given in Table 2 .

Now referring to Figures 2 and 3 it may be observed that $E_{c}$ and $A$ increase with $V_{f}$ signifying an improvement in impact damage tolerance. Table 3 gives $E_{c}$ values for different $V_{f}$ 's. It is worthwhile to point out here that these values are characteristic of the particular material, support conditions and impact velocity.

\section{Effect of Drop Number on Delamination Area}

In order to correlate between delamination mechanism and energy absorption

Table 2. Values of constants.

\begin{tabular}{ccc}
\hline$V_{f}$ & $A$ & $b$ \\
\hline 0.3 & 14.13 & -0.37 \\
0.5 & 17.32 & -0.40 \\
0.7 & 19.85 & -0.39 \\
\hline
\end{tabular}


Table 3. Critical energy values for different " $V_{1}$ 's".

\begin{tabular}{cr}
\hline$V_{1}$ & $E_{c_{\text {soum }}}$ \\
\hline 0.3 & 9.025 \\
0.5 & 9.812 \\
0.7 & 11.173 \\
\hline
\end{tabular}

process in RDTs, the delamination areas were measured at the end of each impact and then plotted against drop number for different $V_{f}$ values as shown in Figure 4.

It can be noted that the delamination area grows initially as the number of impacts increases and reaches a saturation limit. The initial linear increase in delamination area and its attaining a saturation value, clearly implies that the energy absorption (and obviously a major part of the total energy absorbed) is by and large due to delamination process to start with. Once the saturation is reached further impacts are absorbed by other failure processes like fibre breakage and pullout leading to total penetration of the tup through the laminate. This result once again confirms the reasons as to why delamination tendency of laminated composites is by far regarded as the most critical composite chraracteristic that decides their impact damage resistance. The delamination aredigtowths as traced on a transparent sheet are presented in Figure 5 for different. $E_{i n}$ values. The decrease in the number of drops to failure with increase in $E_{i n}$ is clearly seen from this schematic figure.

\section{Effect of $V_{f}$ on Extent of Delamination}

From Figure 6, it can be observed that the delamination area first decreases and then increases as $V_{f}$ is increased. The same trend is seen to prevail for all incident

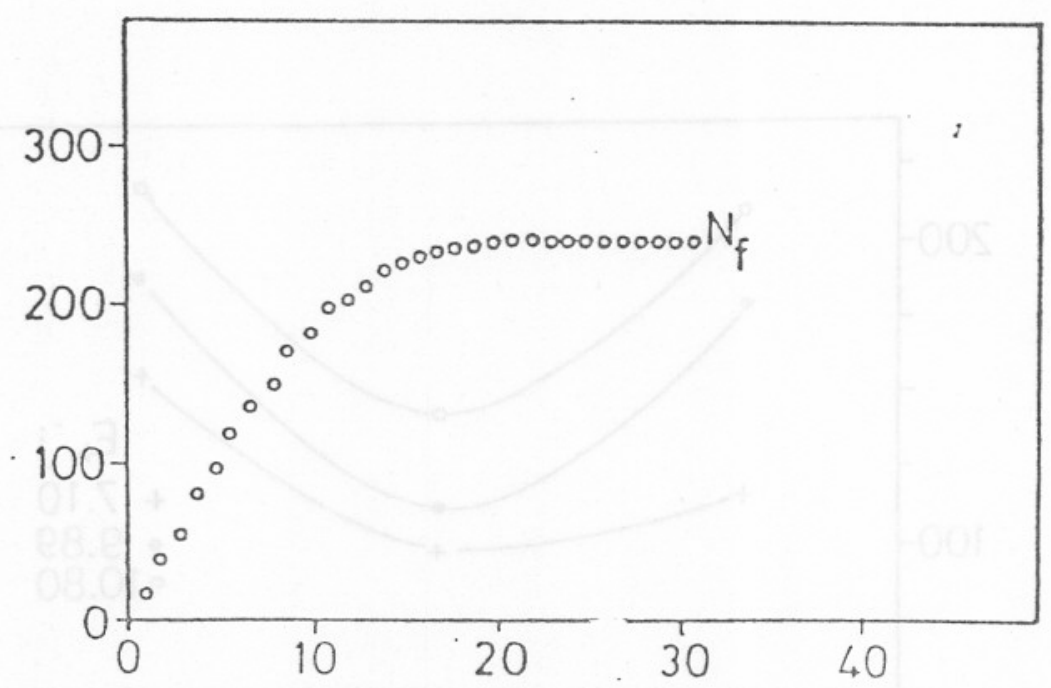

Figure 4. Delamination area vs drop number. Y xis: drop number $\mathrm{N}$; Y-axis: delamination area $\mathrm{mm}^{2}$. 


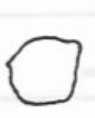

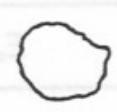

2

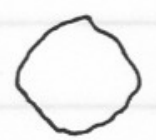

3

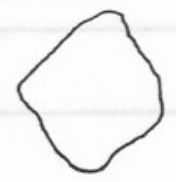

4

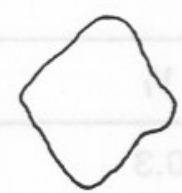

5

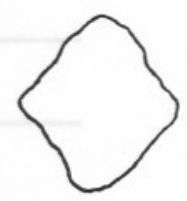

6

AT IIXIDE:T EIERGY OF 7.10 joules

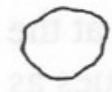

1.

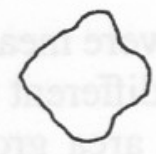

2

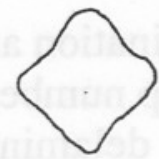

3

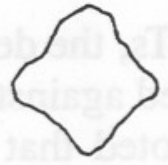

4

AT INELDERT ENTRGY OT 9.89 joules

Figure 5. Delamination area growths as traced on a transparent sheet for laminate of volume fraction 0.5 at two $\mathrm{E}_{\text {in }}$ levels.

energy levels and at any drop number, with the delamination area reaching a minima at a typical $V_{f}=0.5$. This is a very interesting feature observed in all the composite laminates tested. This phenomenon can be attributed to the two failure mechanisms $-[7,8,13]$ dominating in different $V_{f}$ domains as clearly shown in Figure 7. The two mechanisms are as follows

- Extensive matrix crackings percolating down to interface region leading to delamination (dominant below $V_{f}=0,5$ ).

- Decreasing ILSS values causing gross delaminations (dominant above $\left.V_{f}=0.5\right)$.

Thus a minimum delamination is noticed at the cross over point of these two mechanisms.

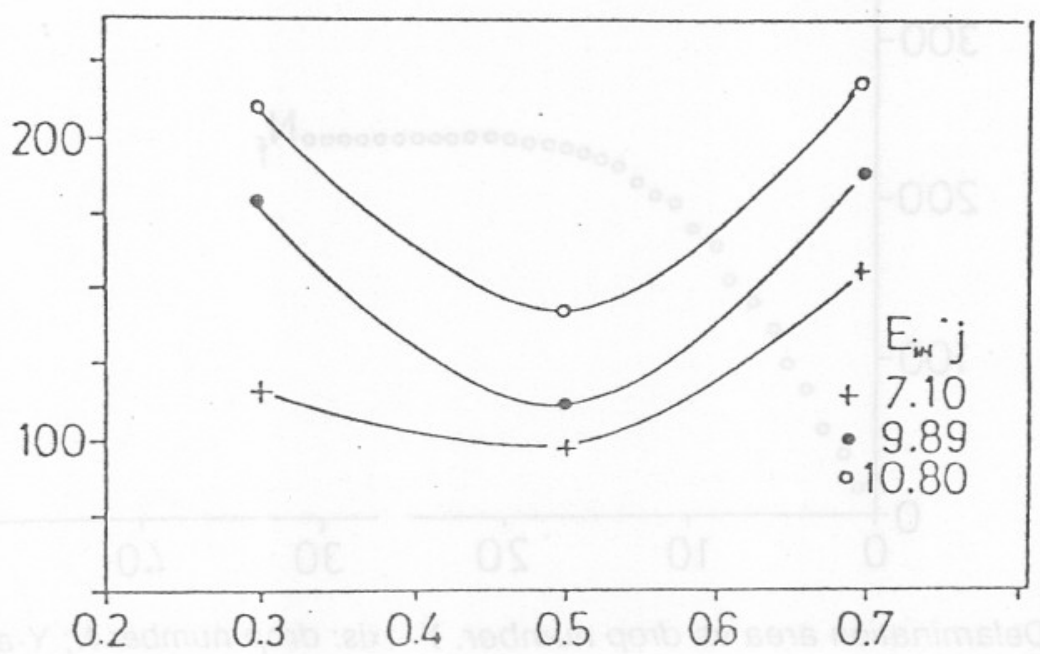

Figure 6. Delamination area vs fiber volume fraction at three incident energy levels. X-axis: fiber volume fraction $\mathrm{V}_{1}$; $\mathrm{Y}$-axis: delamination area $\mathrm{mm}^{2}$. 


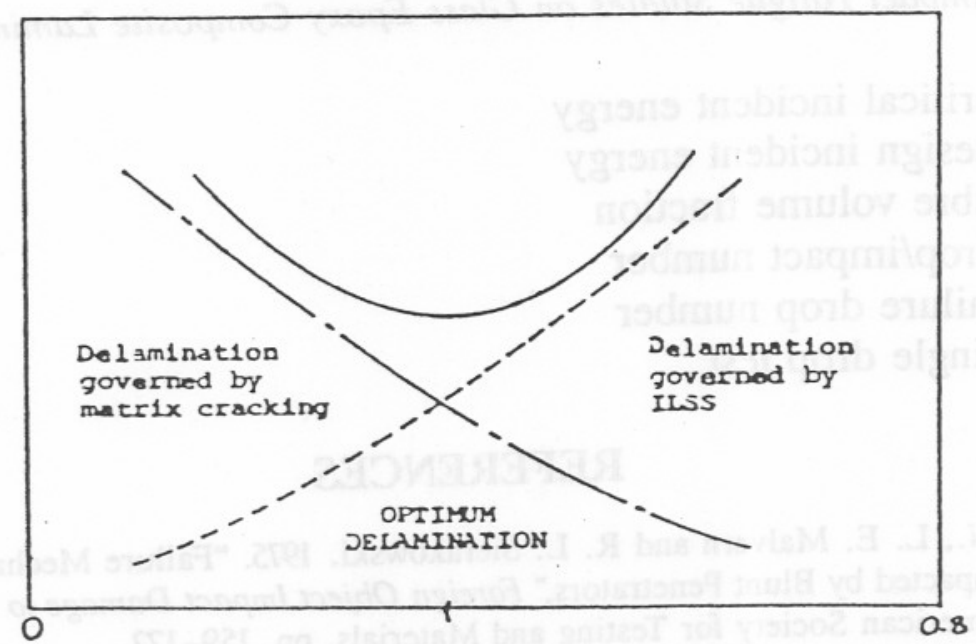

Figure 7. Damage mechanisms operative in different $\mathrm{V}_{\mathrm{f}}$ domains. $\mathrm{X}$-axis: Fiber volume fraction $V_{1} ;$ Y-axis: Delamination area.

\section{CONCLUUSIONS}

An uninstrumented drop weight impact tester has been built and effectively used for impact damage tolerance characterisation of composites laminates.

As the incident energy of the impactor is increased the number of drops to failure decreases. There exists a critical incident energy value which can be evaluated from the impact fatigute curves.

Delamination area grows with energy absorption and reaches a saturation value indicating that energy absorption process changes over from one of delamination to that caused by fibre breakage and pullouts which ultimately lead to penetration of laminate.

Increasing the fibre volume fraction in general results in improved damage tolerance.

The extent of delamination was observed to be least at around $V_{f}=0.5$, which suggest that an optimum delamination occurs when a transition in energy absorption mechanisms take place.

Further studies on other material and test parameters (in progress) are expected to give a more comprehenșive picture of the impact damage tolerance in laminated polymer composites.

\section{ACKNOWLEDGMENTS}

The authors are thankful to Dr. K. N. Raju, Director, Prof. R. Narasimha, ormer Director and Dr. A. K. Singh, Head Materials Science Division, Naional Aerospace Laboratories for all the support they received in the investigaions. They further acknowledge the invaluable assistance received from Mr. K. uresh Raju in the preparation of this paper.

\section{NOMENCLATURE}

$$
E_{\text {in }}=\text { incident energy }
$$


$E_{c}=$ critical incident energy

$E_{d}=$ design incident energy

$V_{f}=$ fibre volume fraction

$N=$ drop/impact number

$N_{f}=$ failure drop number

S.D.T. = single drop test

\section{REFERENCES}

1. Cristescu, N., L. E. Malvern and R. L. Sierakowski. 1975. "Failure Mechanisms in Composite Plates Impacted by Blunt Penetrators," Foreign Object Impact Damage to Composites, ASTM1 STP 568, American Society for Testing and Materials, pp. 159-172.

2. Agarwal, B. D. and L. J. Broutman. 1980. Analysis and Performance of Fibre Composites. John Wiley and Sons.

3. Broutman, L. J. and A. Rotem. 1975. "Impact Strength and Toughness of Fiber Composite Materials," Foreign Object Impact Damage to Composites, ASTM STP 568, American Society for Testing and Materials, pp. 114-133.

4. Amar, C. Garg. 1988. "Delamination-A Damage Mode in Composite Structures," Engineering Fracture Mechanics, 29:557-584.

5. Liu, D. 1988. "Impact Induced Delamination-A View of Bending Stiffness Mismatching," J. of Composite Materials, 22:674-692.

6. Wyrick, D. A. and D. F. Adams. 1988. "Residual Strength of Carbon/Epoxy Composite Material Subjected to Repeated Impact," J: of Composite Materials, 22(8):749-765.

7. Prichard, J. C. and P. J. Hogg. 1990. "The Role of Impact Damage in Post-Impact Compression Testing," Composites, 21(6):503-511.

- 8. Chang, L. 1988. "Impact Fatigue of PPS/Glass Composites," J. of Materials Science Letters, 4:1221-1224.

B.Z 9. Jang, B. P., C. T. Huang, C. Y. Hsieh, W. Kowbel and B. Z. Jang. 1991. "Repeated Impact

and. Failure of Continuous Fibre Reinforced Thermoplastic and Thermoset Composites," $J$. of

Composite Materials, 25:1171-1203.

21910. Kaushal, S., K. Tankala, R. M. V. G. K. Rao and Kishore.1 1991. "Some Hygrothermal Effects $34 y$ on the Mechanical Behavior and Fractography of Glass-Epoxy Composites with Modified Interface," J. of Materials Science, 26:6293-6299.

11. Cantwell, W. J. and J. Morton. 1991. "The Impact Resistance of Composite MaterialsA Review," Composites, 22:347-362.

12. Cantwell, W. J. and J. Morton. 1989. "Geometrical Effects on the Low Velocity Impact Response of CFRP," Composite Structures, 12:46-53.

13. Khan, B. 1992. "Impact Fatigue Behaviour of and Damage Mechanisms in Glass-Epoxy" Composite Laminates," M. tech thesis, KREC/NAL. 